\title{
Effect of a nonsteroidal gametic factor linked to DNA on senile cataract in man
}

\author{
GIUSEPPE LUGARO, ${ }^{1}$ ERNESTO MANERA, ${ }^{1}$ MARIA MADDALENA CASELLATO,${ }^{1}$ \\ EDUARDO MASELLI, ${ }^{2}$ CRISTINA. TALATIN,${ }^{2}$ AND GIUSEPPE FACHINI ${ }^{3}$ \\ From the 'Istituto di Chimica degli Ormoni, CNR, via Mario Bianco 9, I-20131 Milano. ${ }^{2}$ Ospedale Civile di \\ Sondrio, Sezione di Oculistica; and ${ }^{3}$ Laboratorio di Fisiologia e Anatomia, Istituto di Zootecnia, Università di \\ Milano, Italy
}

SUMMARY In view of the results obtained in animal experiments we have studied clinically the effects of administering partially purified gametic extracts to elderly patients with opacity of the lens. Out of 12 patients treated orally or parenterally 10 have shown, on subjective and objective evaluation, a significant increase in vision, a clearing of the opacity of the lens, and an improvement of general mental and physical conditions.

Many experimental data show that the male gamete contains one or more hydrosoluble nonsteroidal and nonhistone factor(s) of low molecular weight (10001500 daltons), probably strongly linked to nuclear chromatin, acting on transcriptional and translational processes in vitro and in vivo. This factor or factors appears to counteract also, temporally and partially, some dysfunctions normally occurring in the later part of mammalian life, the so-called senescence phenomena..$^{1-3}$

The first experimental proof of this activity was reported by Fachini and Gianfranceschi senior in 1964. ${ }^{4}$ These authors achieved evident clearing of the opaque lens in the senile cataract of old dogs by administering parenterally either whole homologous semen or extracts of homologous and heterologous spermatozoa.

Senile cataract is in fact probably one of the more frequent structurally irreversible changes occurring in senescence, and it is a syndrome that, unlike other senile phenomena, may be evaluated almost semiquantitatively. Further data on the same activity were reported by Maselli et al. ${ }^{5}$ in 1972 and recently by Lugaro $e t$ al. ${ }^{\prime}$ in a more extensive research carried out on 43 dogs. At the same time Casellato et al. ${ }^{2}$ have shown that the same active extracts can normalise in senescent rats the inducibility of some liver enzymes (NADPH-oxidase, tyrosine amino transferase, $\boldsymbol{\delta}$-aminolaevulinic acid synthetase, and also Correspondence to Dr G. Lugaro, Istituto di Chimica degli Ormoni, via Mario Bianco 9, I-20131 Milano, Italy. glucokinase), which activity appears to be inversely proportional to the age of the animal. As regards this aspect, Lugaro et al. ${ }^{3}$ have reported that the activity on the enzyme inducibility may be correlated in the aging animal with a significant increase in the rate of liver transcriptional and translational processes.

In view the results we obtained in dogs we decided to investigate this problem in human cataract by giving partially purified gametic extracts by mouth or parenterally.

\section{Material and methods}

Bovine spermatozoa were obtained, as described below, from total semen containing about $10^{\circ} \mathrm{cells} / \mathrm{ml}$.

Extraction and purification of the gametic factor for parenteral use. The whole process of extraction and purification of the gametic factor was done as previously reported. ${ }^{1}$ We started not from a gamete homogenate in toto but from dried and lipid-free spermatozoa, isolated from bovine semen according to Borenfreund et al. ${ }^{6}$ with minor modifications.

The purified extract was ultrafiltered and passed again through a sterilising membrane (porosity $0 \cdot 23 \mu \mathrm{m}$, Millipore), then lyophilised in the presence of glycine as substrate. The samples were sterile, protein-free, and pyrogen-free.

Extraction of the gametic factor for oral use. Dried and lipid-free spermatozoa isolated as described above were accurately homogenised with corindone in saline ( $50 \mathrm{mM}$ sodium chloride), and the suspen- 
Table 1 Summary of the results obtained in 6 subjects after 21-day oral treatment (see text). First examination, at the end of treatment; second examination, 30-40 days later. In brackets are indicated the optical corrections employed to obtain these values of visual acuity

\begin{tabular}{|c|c|c|c|c|c|c|c|c|}
\hline \multirow{2}{*}{$\begin{array}{l}\text { Patient } \\
\text { no. }\end{array}$} & \multirow[t]{2}{*}{ Sex } & \multirow{2}{*}{$\begin{array}{l}\text { Age } \\
\text { (years) }\end{array}$} & \multirow[t]{2}{*}{ Eye } & \multirow[t]{2}{*}{ Fundus } & \multirow[t]{2}{*}{ Lens opacities } & \multicolumn{3}{|l|}{ Vision } \\
\hline & & & & & & Before treatment & Ist examination & 2nd examination \\
\hline \multirow[b]{2}{*}{1} & \multirow{2}{*}{$\mathrm{F}$} & \multirow[b]{2}{*}{80} & \multirow{12}{*}{$\begin{array}{l}\mathbf{R} \\
\mathbf{L} \\
\mathbf{R} \\
\mathbf{L} \\
\mathbf{R} \\
\mathbf{L} \\
\mathbf{R} \\
\mathbf{L} \\
\mathbf{R} \\
\mathbf{L} \\
\mathbf{R} \\
\mathbf{L}\end{array}$} & \multirow{2}{*}{ Miopic choroidosis } & Corticonuclear & Counting fingers & Counting fingers & $1 / 50(-20)$ \\
\hline & & & & & Cortical & $3 / 50(-20)$ & $1 / 10(-22)$ & $2 / 10(-22)$ \\
\hline \multirow[b]{2}{*}{2} & \multirow[b]{2}{*}{$\mathbf{M}$} & \multirow[b]{2}{*}{82} & & \multirow[b]{2}{*}{ Vascular sclerosis } & SCortical and & $1 / 20(-5)$ & $2 / 10(-4)$ & $2 / 10(-3)$ \\
\hline & & & & & posterior subcapsular & $1 / 20(-5)$ & $1 / 20(-5)$ & $1 / 20(-5)$ \\
\hline \multirow{2}{*}{3} & \multirow{2}{*}{$\mathbf{F}$} & \multirow{2}{*}{85} & & \multirow{2}{*}{ Diabetic retinopatia } & SCortical and & $1 / 50(-1 \cdot 5)$ & $1 / 50$ & \\
\hline & & & & & nuclear & $1 / 10(-1 \cdot 5)$ & $1 / 10$ & \\
\hline \multirow{2}{*}{4} & \multirow{2}{*}{$\mathbf{M}$} & \multirow{2}{*}{85} & & \multirow{2}{*}{ Papillaris cupping } & SCortical, nuclear, & $3 / 10(-7)$ & $3 / 10(-7)$ & $5 / 10(-7)$ \\
\hline & & & & & and subcapsular & $4 / 10(-5 \cdot 5)$ & $5 / 10(-5 \cdot 5)$ & $5 / 10(-5)$ \\
\hline \multirow{2}{*}{5} & \multirow{2}{*}{$\mathrm{F}$} & \multirow{2}{*}{88} & & \multirow{2}{*}{ Vascular sclerosis } & SCortical and & $5 / 10(+1)$ & $5 / 10(+1)$ & $7 / 10(+0 \cdot 5)$ \\
\hline & & & & & Subcapsular & $1 / 20(+1)$ & $1 / 20(+1)$ & $4 / 10(-0.5)$ \\
\hline \multirow{2}{*}{6} & \multirow{2}{*}{$\mathbf{M}$} & \multirow{2}{*}{75} & & \multirow{2}{*}{ Vascular sclerosis } & SCoronary and & $4 / 10(-1)$ & $6 / 10(+0.75)$ & $8 / 10(+1 \cdot 5)$ \\
\hline & & & & & Cortical & Counting fingers & $3 / 50$ & $3 / 50(+1 \cdot 5)$ \\
\hline
\end{tabular}

sion centrifuged at $5000 \mathrm{~g}$ for $30 \mathrm{~min}$ : To one volume of supernatant was added one volume of $0.4 \mathrm{M}$ ammonium acetate-ammonia buffer $\mathrm{pH} 9 \cdot 5$. After precipitation overnight in the cold with two volumes of $95 \%$ ethanol, and subsequent centrifugation at $13000 \mathrm{~g}$ for $30 \mathrm{~min}$, the supernatant was evaporated to a small volume under vacuum at $30^{\circ}-35^{\circ} \mathrm{C}$. The concentrated solution, brought to $\mathrm{pH} 9.5$ with dilute ammonia, was ultrafiltered through a membrane with a porosity less than $5 \mathrm{~nm}$ (Sartorius Membranfilter 12136 , mol. wt. cut off 10000 daltons) and then lyophilised twice. A third lyophilisation was conducted after mixing with an inert compound (glycine).

Steroid content. The presence of free steroids or their conjugates in the extracts was excluded (before and after enzymatic digestion with glucuronidase and sulphatase) by radioimmunoassay for testosterone, $5 \alpha$-dihydrotestosterone, progesterone, and $17 \beta$-estradiol $(<5 \mathrm{pg}$ for fraction equivalent to about $10^{9}$ spermatozoa or $1 \mathrm{ml}$ of total semen.)
Treatment. The clinical assay was carried out in 16 elderly patients, all proposed for surgical operation, between 74 and 88 years old, suffering from mono- or bilateral senile cataract. Six patients were treated by mouth, 6 parenterally, and 4 with a placebo (glycine). In the case of oral administration the treatment lasted for 21 days with a quantity of the extract equivalent to about $10^{10}$ spermatozoa daily. In the case of parenteral administration, two intramuscular injections with a 12-h interval, each equivalent to the extract of $2.5 \times 10^{8}$ spermatozoa/ $\mathrm{kg}$ body weight, were given.

Orally treated subjects were submitted to a careful inspection of the eyes before the treatment, at the end (1st control), and 30-40 days later (2nd control). Subjects parenterally treated were examined before, 2-6 days after treatment (1st control), and 2-3 weeks later (2nd control).

The examination of the vision and refractory status with the pupil in normal condition, and on biomicro-

Table 2 Summary of the results obtained in 6 subjects after parenteral treatment (see text). First examination, 2-6 days after treatment; second examination, 2-3 weeks later. In brackets are indicated the optical corrections employed to obtain these values of visual acuity

\begin{tabular}{|c|c|c|c|c|c|c|c|c|}
\hline \multirow{2}{*}{$\begin{array}{l}\text { Patient } \\
\text { no. }\end{array}$} & \multirow[t]{2}{*}{ Sex } & \multirow{2}{*}{$\begin{array}{l}\text { Age } \\
\text { (years) }\end{array}$} & \multirow[t]{2}{*}{ Eye } & \multirow[t]{2}{*}{ Fundus } & \multirow[t]{2}{*}{ Lens opacities } & \multicolumn{3}{|l|}{ Vision } \\
\hline & & & & & & Before treatment & Ist examination & 2nd examination \\
\hline $1 p$ & $\mathbf{M}$ & 75 & $\begin{array}{l}\mathbf{R} \\
\mathbf{L}\end{array}$ & $\begin{array}{l}\text { Normal } \\
\text { Miopic choroidosis }\end{array}$ & $\left\{\begin{array}{l}\text { Posterior } \\
\text { subcapsular }\end{array}\right.$ & $\begin{array}{l}1 / 10 \\
\text { Amblyopia }\end{array}$ & $\begin{array}{l}2 / 10 \\
\text { Amblyopia }\end{array}$ & \\
\hline $2 p$ & F & 76 & $\begin{array}{l}\mathbf{R} \\
\mathbf{L}\end{array}$ & $\{$ Normal & $\left\{\begin{array}{l}\text { Cortical and } \\
\text { subcapsular }\end{array}\right.$ & $\begin{array}{l}1 / 10 \\
1 / 10\end{array}$ & $\begin{array}{l}2 / 10 \\
2 / 10\end{array}$ & $\begin{array}{l}1 / 10 \\
1 / 10\end{array}$ \\
\hline $3 p$ & $\mathrm{~F}$ & 80 & R & $\{$ Normal & $\{$ Cortical & $\begin{array}{l}2 / 10 \\
2 / 10\end{array}$ & $\begin{array}{l}3 / 10 \\
3 / 10\end{array}$ & $\begin{array}{l}3 / 10 \\
3 / 10\end{array}$ \\
\hline $4 p$ & $\mathbf{M}$ & 83 & $\begin{array}{l}\mathbf{R} \\
\mathrm{L}\end{array}$ & $\{$ Vascular sclerosis & $\left\{\begin{array}{l}\text { Cortical and } \\
\text { subcapsular }\end{array}\right.$ & $1 / 20$ & $1 / 10$ & $3 / 10$ \\
\hline $5 p$ & $\mathrm{~F}$ & 74 & $\begin{array}{l}\mathbf{R} \\
\mathbf{L}\end{array}$ & $\{$ Normal & $\left\{\begin{array}{l}\text { Anterior and } \\
\text { posterior cortical }\end{array}\right.$ & $3 / 10(-3)$ & $4 / 10(-3)$ & \\
\hline $6 p$ & $\mathbf{F}$ & 74 & $\begin{array}{l}\mathbf{R} \\
\mathbf{L}\end{array}$ & $\{$ Normal & $\{$ Cortical & $\begin{array}{l}6 / 10(+1 \cdot 5) \\
1 / 10(+1 \cdot 5)\end{array}$ & $\begin{array}{l}6 / 10 \\
1 / 10\end{array}$ & \\
\hline
\end{tabular}




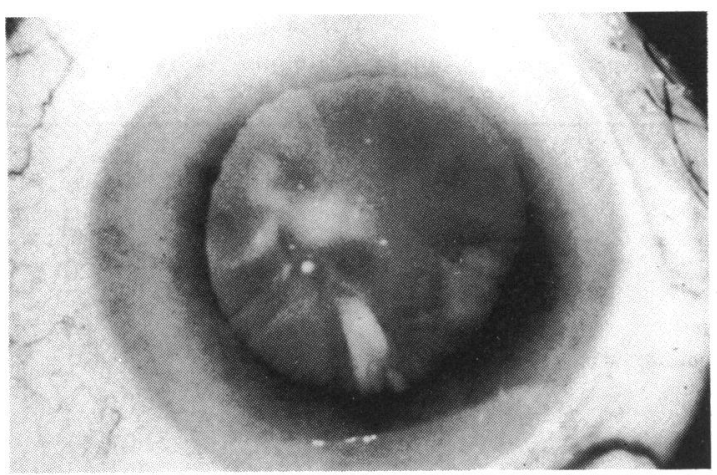

Fig.1A

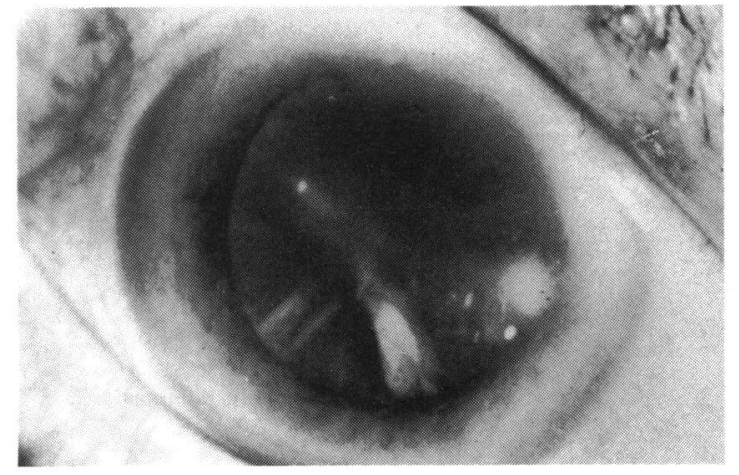

Fig. 1B

Fig. 1 Photobiomicroscopy of the crystalline lens of the left eye opacified from senile cataract in patient 5 (see Table 1), before $(A$, vision $1 / 20)$ and after $(B$, vision $4 / 10)$ oral treatment (second examination).

scopic inspection of the lens under mydriasis, was carried out with a slit-lamp and an ophthalmoscope.

\section{Results}

Tables 1 and 2 show the results in treated patients. In the 6 treated by mouth the data (Table 1) show a variable increase in visual acuity, which is shown also by the objective evaluation of the lens. Patients 5 (Fig. 1) and 6 showed the best subjective and objective improvement. In patient 1 (Fig. 2) the increase in vision was satisfactory, as was the related clearing of the lens, particularly in the left eye. Patients 2 and 4 had less improvement, but it was significant. Patient 3 did not come back for the second examination, so any evaluation was impossible.

The vision of the 4 placebo-treated patients was unaltered.
As to the 6 parenterally treated subjects (Table 2), we observed evident improvement of the right eye vision in patient $4 \mathrm{p}$. A slight increase in vision was observed also in patients $1 \mathrm{p}, 2 \mathrm{p}$, and $3 \mathrm{p}$, although in $2 p$ the increase seemed to be transient; in fact it was no more appreciable at the second examination than earlier. Patients $5 p$ and $6 p$ did not come back for the second examination; patient $6 \mathrm{p}$ did not show any variation at the first examination.

\section{Discussion}

These findings show that the gametic factor can induce, at least in some subjects, an evident clearing of the initial opacities, chiefly in the cortical layer of the lens. The biomicroscopic observations show a lessening in the typical milky aspect of the lens and a break of the less thick opacities in the cortical layer.

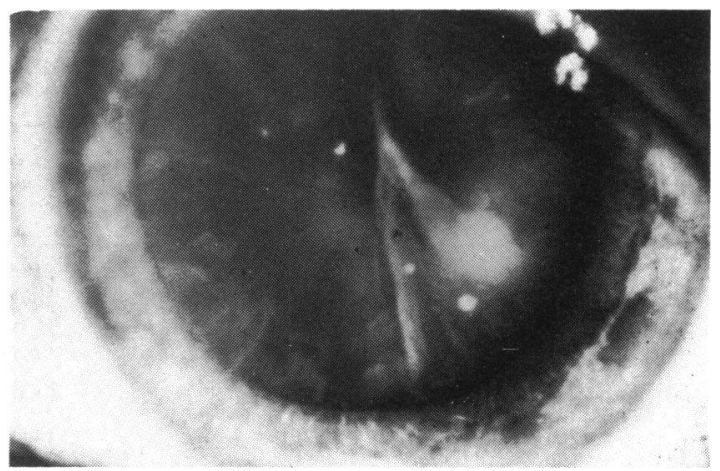

Fig. 2B

Fig. 2A

Fig. 2 Photobiomicroscopy of the crystalline lens of the left eye opacified from senile cataract in patient 1 (see Table 1), before $(A$, vision $3 / 50)$ and after $(B$, vision $2 / 10)$ oral treatment (second examination). 
It would seem, then, that cortical cataract may yield the best results from treatment, while nuclear or posterior subcapsular opacities generally show a minor clearing. In the latter case the partial improvement of vision can be referred only to the clearing of the cortical opacities.

At the same time it is possible to see an objective and a subjective improvement in general health conditions (wellbeing, muscular tone, mental alertness, etc). Among these 'side effects' of the therapy, it is interesting to underline the lessening, in number and intensity, of the so-called maculae cutaneae senilis, the brownish cutaneous spots which occur typically on the back of the hands in old people. As noted previously, ${ }^{1}$ we do not know the mechanism of this temporary correction. The results seem to reflect, in the individual and in the organs, what has already been widely observed in haematological, biochemical, cellular, and subcellular variables. ${ }^{7}$

The active factor, which may be a peptide ${ }^{1}$ or a family of peptides of low molecular weight naturally linked to nuclear chromatin, exerts an inhibitory action when it is, conversely, in accelerated cytokinetic or cytodynamic conditions (for instance, in a young growing organism). This was shown in trials carried out on the $\delta$-aminolaevulinic acid synthetase inducibility in prepuberal rats, ${ }^{3}$ where, in contrast to what takes place in aging rats, the inducibility is significantly decreased owing to a direct action in the transcriptional and translational processes.

This fact leads us to suggest that the considered factor(s) would act as general factor of homoeostasis in more complex mechanisms which control the basal processes of gene expression. ${ }^{8}$

This work was supported by the Programma Finalizzato Biologia della Riproduzione (CNR, Italy).

\section{References}

1 Lugaro G, Casellato MM, Manera E, Bacigalupo MA, Maselli E, Fachini $G$. Effect of a nonsteroidal gametic factor on senile cataract in the dog. Br J Ophthalmol 1980; 64: 315-7.

2 Casellato MM, Manera E, Riboni L, Comolli R, Lugaro G. Activity of a purified nonsteroidal gametic factor on the inducibility of hepatic $\delta$-aminolevulinic acid synthase, NADPH-oxidase and tyrosine aminotransferase in senescent rats. Cancer Biochem Biophys 1980; 4: 245-9.

3 Lugaro G, Manera E, Casellato MM, Riboni L. A nonsteroidal gametic factor linked to DNA modulates $\delta$-aminolevulinic acid synthase inducibility acting on liver transcriptional and translational processes. Submitted for publication.

4 Fachini G, Gianfranceschi G senior. Gametes and senescence. Experientia 1964; 20: 404-5.

5 Maselli E, Fachini G, Lugaro G. Sugli effettidi un estrattogametico nella cataratta senile. Atti del LIV Congresso della Società Oftalmologica Italiana. Rome, 1972.

6 Borenfreund E, Fitt E, Bendich A. Isolation and properties of deoxyribonucleic acid from mammalian sperm. Nature 1961; 191: 1375-7.

7 Fachini G, Cazzea G, Gianfranceschi G sen, Casellato MM, Lugaro G. Information and senescence (proposal of a model). Rum J Physiol 1977; 14: 193-206.

8 Lugaro G. Manera E, Casellato MM, Sanso M, Leonardi MG, Fachini G. Low molecular weight gametic factor linked to DNA and homeostatic processes. 1st International Symposium 'Regulation of Gene Expression by Low Molecular Weight Peptides.' Rende, 1982. 